\title{
Selective purging of human multiple myeloma cells from peripheral blood mononuclear cells: a preliminary study
}

This article was published in the following Dove Medical Press journal: Journal of Blood Medicine

\author{
A-Jin Lee \\ Sang-Gyung Kim \\ Department of Laboratory Medicine, \\ Daegu Catholic University School of \\ Medicine, Daegu, Korea
}

\begin{abstract}
Background: High-dose chemotherapy followed by autologous peripheral blood stem-cell transplantation are standards of therapy for patients diagnosed with multiple myeloma. The purging process to remove contaminating residual myeloma cells could improve patient outcomes. In this study, a purging method of human multiple myeloma cells from peripheral blood mononuclear cells was evaluated.
\end{abstract}

Materials and methods: The human myeloma cell line RPMI-8226 (Seoul, Korea) was treated with bortezomib (Selleck Chemicals, Houston, TX, USA) or lenalidomide (Sigma Aldrich, St. Louis, MO, USA). The mixture of the human peripheral blood mononuclear cell line PCS800-011 (ATCC, USA) and RPMI-8226 was treated with bortezomib or lenalidomide for 24 hours. The efficacy of purging myeloma cells was evaluated by 8 -color flow cytometric analysis. Results: The cytotoxicity of bortezomib (10-160 nmol/L) and lenalidomide (200-3,200 nmol/L) was investigated on RPMI-8226 myeloma cell line. A 24-hour incubation with bortezomib at 10 , $20,40,80,160 \mathrm{nmol} / \mathrm{L}$ induced $5.45 \% \pm 0.07 \%, 47.15 \% \pm 1.20 \%, 57.15 \% \pm 0.21 \%, 72.35 \% \pm 0.07 \%$, and $84.75 \% \pm 0.49 \%$ growth inhibition in RPMI-8226 cells, respectively. A 24-hour incubation with lenalidomide at $200,400,800,1,600$, and $3,200 \mathrm{nmol} / \mathrm{L}$ induced $5.45 \% \pm 0.07 \%$, $7.55 \% \pm 0.07 \%, 9.75 \% \pm 0.35 \%, 18.25 \% \pm 0.21 \%$, and $39.75 \% \pm 0.78 \%$ growth inhibition in RPMI8226 cells, respectively. Bortezomib ( $40 \mathrm{nmol} / \mathrm{L}, 24$ hours) and lenalidomide (3,200 nmol/L, 24 hours) effectively removed $\mathrm{CD} 38^{+} \mathrm{CD} 138^{+}$cells from peripheral mononuclear cells. RPMI-8226 cells showed abberant phenotype $\mathrm{CD} 56^{+} / \mathrm{CD} 45^{-}$.

Conclusion: The results of the present study demonstrated that the bortezomib and lenalidomide treatment in RPMI-8226 multiple myeloma cells effectively removed the contaminated plasma cells.

Keywords: multiple myeloma, bortezomib, lenalidomide, bone marrow purging, hematopoietic stem cell transplantation

\section{Introduction}

Multiple myeloma (MM) is a neoplastic plasma cell disorder which is characterized by a clonal proliferation of malignant, monoclonal plasma cells in the bone marrow and/ or extramedullary sites. ${ }^{1}$ High-dose chemotherapy followed by autologous peripheral blood stem-cell transplantation (PBSCT) are standards of therapy for selected patients diagnosed with MM. ${ }^{1,2}$ In recent years, the introduction of therapeutic agents such as thalidomide, bortezomib (Velcade, PS-341), and lenalidomide have markedly prolonged overall survival (OS) for MM patients. ${ }^{3}$ Even though progress in OS rates has been achieved by a variety of treatment options, MM still remains an incurable disease and the tumor relapse rate is high. ${ }^{4}$
Correspondence: A-Jin Lee Department of Laboratory Medicine, Daegu Catholic University School of Medicine, 33, Duryugongwon-ro 17-gil, Nam-gu, Daegu 42472, Korea

Tel +8253 6504102

Fax +82536538672

Email ajlee388@gmail.com 
Relapse may be due to the insufficient eradication of malignant plasma cells by high-dose chemotherapy and the reinfusion of residual malignant plasma cells with the PBSCT. It has been reported that MM graft contamination leads to poor outcome following transplantation. ${ }^{5}$ According to plasma cell contamination burden in graft ("low" level $\left(<4.5 \times 10^{5}\right.$ plasma cells $\left./ \mathrm{kg}\right)$ or "high" level $\left(\geq 4.5 \times 10^{5}\right.$ plasma cells $/ \mathrm{kg}$ ), the "low" level graft contamination group has shown lower progression free survival. ${ }^{6}$ Syngeneic twin transplantation has shown significantly lower relapse risk than autologous transplantation in MM patients. ${ }^{7}$ These observations suggest that even low levels of MM cells contaminating the autograft can impact the course of disease and patient outcome. Ex vivo manipulation of the autograft prior to infusion to remove contaminating residual myeloma cells, a process called purging, could improve MM patient outcomes. ${ }^{8}$ Several methods of ex vivo purging technique have been described, that is, CD34+ cell selection, chemotherapeutic agents, and viral-based methods. ${ }^{9-11}$ However, no definite method has been generally adopted into the clinical setting.

Therefore, we postulated that the removal of remnant plasma cells might be an important factor to prevent the tumor relapse. In this study, the multiple myeloma cell line RPMI-8226 was treated with various concentrations of chemotherapeutic drugs, followed by determination of proper concentrations. Then, a purging method of human multiple myeloma cells from peripheral blood mononuclear cells was developed using chemotherapeutic drug treatment, and the efficacy of myeloma cell removal was evaluated using the flow cytometric method.

\section{Materials and methods}

\section{Cell lines and cell culture}

The human myeloma cell line RPMI-8226 was obtained from the Korean Cell Line Bank (Seoul, Korea) and the human peripheral mononuclear cell line PCS-800-011 $1^{\mathrm{TM}}$ was obtained from American Type Culture Collection. Cells were cultured at $37^{\circ} \mathrm{C}, 5 \% \mathrm{CO}_{2}$ in a humidified incubator in RPMI medium (Gibco/BRL, Grans Island, NY) containing $10 \%$ FBS (Gibco/BRL).

\section{Single-drug treatment of myeloma cell lines}

Bortezomib (Selleck Chemicals, Houston, TX) or lenalidomide (Sigma Aldrich, St. Louis, MO) was used to treat RPMI-8226 cells for the purpose of determining the proper concentration. RPMI-8226 cells were inoculated in duplicate in flat-bottomed 96-well plates at $5 \times 10^{3}$ cells/ well and treated with drug. One group of RPMI-8226 cells were treated with a range of concentrations of bortezomib (10-100 nmol/L) for 24 hours. The other group of RPMI8226 cells were treated with a range of concentrations of lenalidomide (200-3,200 nmol/L) for 24 hours. The control group of cells were treated with PBS (for untreated 100\% survival control). Cells were incubated at $37^{\circ} \mathrm{C}$ in a $5 \%$ $\mathrm{CO} 2$ humidified atmosphere.

\section{Cell viability assay}

A cell viability assay was performed using the cell counting kit-8 (CCK-8) assay (Sigma-Aldrich) according to the manufacturer protocol. After drug treatment, $10 \mu \mathrm{L}$ of CCK- 8 was added to each well and incubated at $37^{\circ} \mathrm{C}$ for 4 hours. Then, the absorbance was determined at $450 \mathrm{~nm}$. A dose-inhibition curve was drawn from the results of the CCK-8 assay by calculating the percentage of cell viability $(100 \times$ absorbance of drug treated wells/absorbance of control wells).

\section{Flow cytometric analysis}

PCS-800-011 ${ }^{\mathrm{TM}}$ was admixed with RPMI-8226 cells to result in a tumor burden of 1:100-5:100 to simulate the contaminated plasma cells in mononuclear cells. The cell mixture was treated with bortezomib or lenalidomide for 24 hours. The presence of myeloma cells in pretreatment and posttreatment was evaluated by flow cytometric analysis. Briefly, at each time point, a $500 \mu \mathrm{L}$ cell suspension was prepared. The cell density was at least $5 \times 10^{5}$ cells $/ \mathrm{mL}$. To the cells, $2 \mathrm{~mL}$ PBS was added and then gently mixed. The tubes were centrifuged for 5 minutes at $540 \mathrm{~g}$ and the supernatant was removed. The washing with PBS and removal of the supernatant were repeated twice. Then, cells were stained with fluorochromeconjugated antibodies. The following combinations were used during flow cytometric analysis: tube 1, anti-CD38fluorescein isothiocyanate (FITC)/anti-CD56-phycoerythrin (PE)/anti-CD45- peridinin chlorophyll-A protein cyanine5.5 (PerCP Cy5.5)/anti-CD19- phycoerythrin-cyanine7 (PC7)/ anti-CD117-allophycocyanin (APC)/anti-CD81-allophycocyanin-H7 (APCH7)/anti-CD138-V450/anti-CD27-BV510; tube 2, anti-CD38-FITC/anti-CD56-PE/anti-CD45-PerCP Cy5.5/anti-CD19-PC7/anti-cIgK-APC/anti-cIg $\lambda$-APCH7/ anti-CD138-V450/anti-CD27-BV510 (BD Biosciences, San Jose, CA). Flow cytometric immunophenotyping was performed using FACSCanto II (BD Biosciences). Data were analyzed using FACSDiva software (BD Biosciences). 
Plasma cell population gate was set on the basis of a combination of forward and side light scatter and expression of CD38, CD138, and CD45.

\section{Results}

\section{Cytotoxicity of bortezomib or lenalidomide on myeloma cell line}

The cytotoxicity of bortezomib (10-160 nmol/L) and lenalidomide (200-3,200 nmol/L) was investigated on the RPMI-8226 myeloma cell line. A 24-hour incubation with bortezomib at 10, 20, 40, 80, $160 \mathrm{nmol} / \mathrm{L}$ induced $5.45 \% \pm 0.07 \%, 47.15 \% \pm 1.20 \%, 57.15 \% \pm 0.21 \%$, $72.35 \% \pm 0.07 \%$, and $84.75 \% \pm 0.49 \%$ growth inhibition in RPMI-8226 cells, respectively (Figure 1). A 24-hour incubation with lenalidomide at 200, 400, 800, 1,600, and $3,200 \mathrm{nmol} / \mathrm{L}$ induced $5.45 \% \pm 0.07 \%, 7.55 \% \pm 0.07 \%$, $9.75 \% \pm 0.35 \%, 18.25 \% \pm 0.21 \%$, and $39.75 \% \pm 0.78 \%$ growth inhibition in RPMI-8226 cells, respectively (Figure 1). The $40 \mathrm{nmol} / \mathrm{L}$ bortezomib dose and 3,200 $\mathrm{nmol} / \mathrm{L}$ lenalidomide dose were adopted for further investigation.

\section{Efficacy of bortezomib and lenalidomide on admixed myeloma cells and peripheral blood mononuclear cells}

The efficacy of myeloma cell removal was analyzed by flow cytometry for each step. Clonal $\mathrm{CD} 38^{+} \mathrm{CD} 138^{+}$cells expressed CD27, CD81, CD117, CD56, and $\operatorname{cIg} \lambda$. These cells showed the absence of CD19 and CD45. Bortezomib treatment ( $40 \mathrm{nmol} / \mathrm{L}, 24$ hours) on admixture of plasma cells and mononuclear cells $(5: 100)$ reduced the number of CD $38^{+} \mathrm{CD} 138^{+}$cells from $5.1 \%$ to $0.0 \%$ with no effect on
$\mathrm{CD} 19^{+}$cells (Figure 2). Bortezomib treatment (40 nmol/L, 24 hours) on admixture of plasma cells and mononuclear cells $(1: 100)$ reduced the number of $\mathrm{CD} 38^{+} \mathrm{CD} 138^{+}$cells from $1.2 \%$ to $0.0 \%$ (Figure 2 ). Lenalidomide $(3,200 \mathrm{nmol} / \mathrm{L}$, 24 hours) on admixture of plasma cells and mononuclear cells also effectively removed the $\mathrm{CD} 38^{+} \mathrm{CD} 138^{+}$plasma cells (Figure 2).

\section{Discussion}

In this study, the applicability of using chemotherapeutic drug as a potential removing agent for myeloma cells was evaluated. The RPMI-8226 cell line was treated with various concentrations of bortezomib and lenalidomide. Our results indicated that both drugs inhibited the proliferation of RPMI8226 cells in a dose-dependent manner.

Bortezomib has been reported to be highly cytotoxic to myeloma cell lines through selective $20 \mathrm{~S}$ proteasome inhibition. ${ }^{12}$ The ubiquitin-proteasome pathway has been demonstrated to be one of the most important systems contributing to multiple myeloma pathophysiology. This system consists of the $26 \mathrm{~S}$ proteasomes, ubiquitin, ubiquitin-related enzymes, and deubiquitinases. The $26 \mathrm{~S}$ proteasomes, consisting of a core 20S catalytic complex and a 19S regulatory complex, have been demonstrated to be good biomarkers for MM therapeutic monitoring. ${ }^{13}$ The bortezomib is a dipeptidyl boronate. The boron atom in bortezomib targets the chymotrypsin- and caspase-like active sites of the 20S core of the proteasome, with a minimal effect on the trypsin-like activity. ${ }^{14}$ In this study, bortezomib efficiently depleted $\mathrm{CD} 38^{+} \mathrm{CD} 138^{+}$myeloma cells from peripheral blood mononuclear cells. Bortezomib has been demonstrated to inhibit the growth of myeloma cells in vitro. ${ }^{10,15}$ The efficacy of

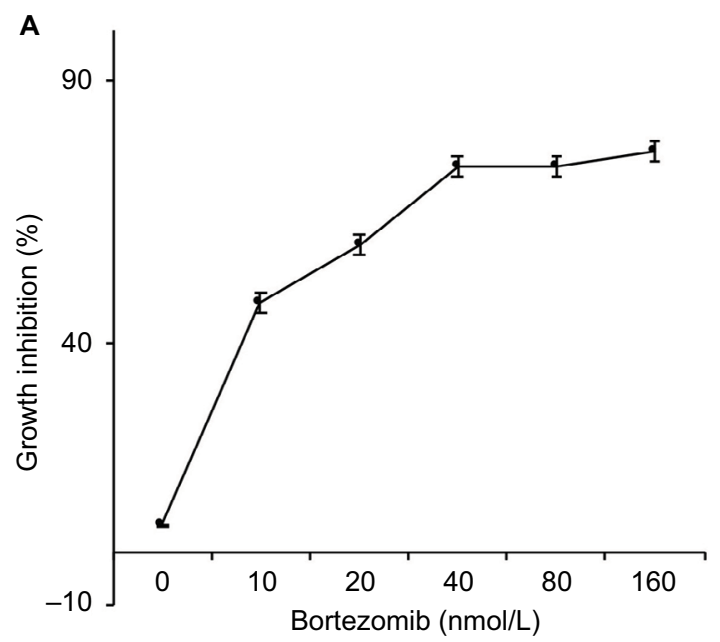

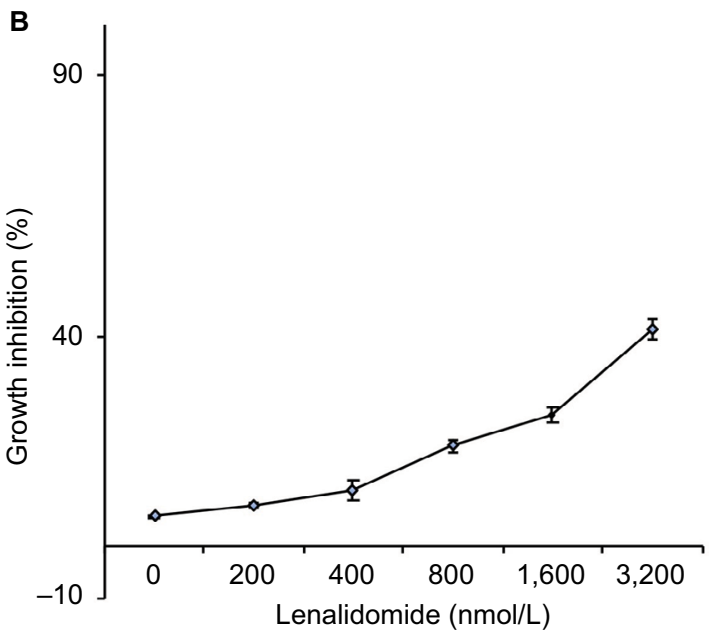

Figure I Growth inhibition of RPMI-8226 cells treated by different concentrations of bortezomib (A) or lenalidomide (B) for 24 hours. 
A

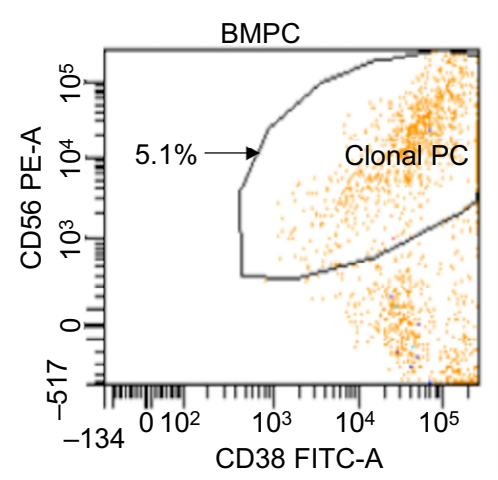

C

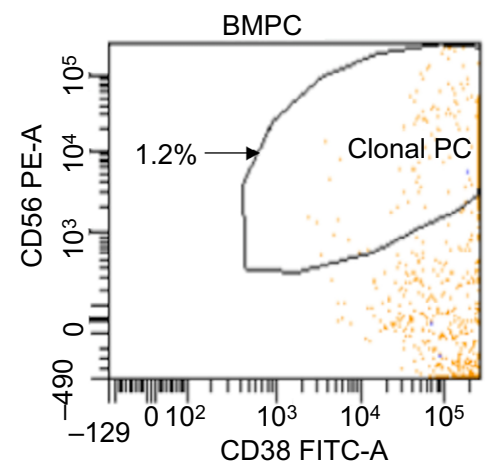

B

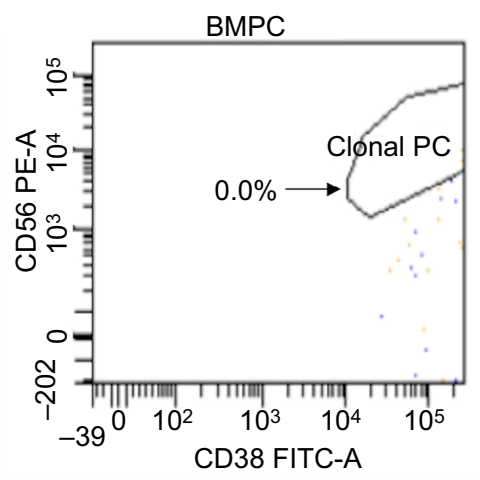

D

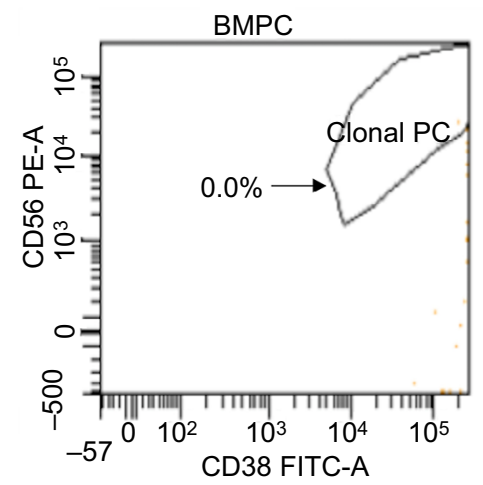

Figure 2 Flow cytometric analysis. Admixture of plasma cells and mononuclear cells (5:100) (A) were removed after treatment with bortezomib for 24 hours (B). Admixture of plasma cells and mononuclear cells (I:100) (C) were removed after treatment with lenalidomide for 24 hours (D).

Abbreviation: BMPC, bone marrow plasma cells.

purging was evaluated using flow cytometry and PCR in 16 patient apheresis products and 3-4 log depletion of the tumor was reported. ${ }^{10}$

Lenalidomide, a derivative of thalidomide, is an immunomodulatory drug. Lenalidomide has been demonstrated to have a growth inhibitory effect on MM cell lines, while protecting normal B-cells from apoptosis. ${ }^{16}$ In the present study, lenalidomide removed the $\mathrm{CD} 38^{+} \mathrm{CD} 138^{+}$plasma cells.

A multiparametric flow cytometric method was performed to discriminate between clonal and nonclonal plasma cells in the present study. RPMI-8226 cells expressed two aberrant phenotypes of $\mathrm{CD} 19^{-} \mathrm{CD} 56^{+}$. These clonal cells were effectively removed by treatment with bortezomib and lenalidomide. The expression of differentiation markers was consistent with the results of a previous study. ${ }^{17}$

In conclusion, the results of the present study demonstrated that the bortezomib treatment in RPMI-8226 multiple myeloma cells effectively removed the contaminated plasma cells. Overall, these data, if applicable to patient derived stem cell grafts, may improve the cure rate in multiple myeloma patients.

\section{Acknowledgments}

This work was supported by a grant of the Research Institute of Medical Science, Daegu Catholic University (2016). The abstract of this paper was presented at the 35th International Congress of the ISBT as a poster presentation with interim findings. The poster's abstract has not yet been published in "ISBT Science Series".

\section{Disclosure}

The authors report no conflicts of interest in this work.

\section{References}

1. PalumboA,Anderson K. Multiple myeloma. NEnglJMed.2011;364(11): 1046-1060.

2. Palumbo A, Cavallo F. Have drug combinations supplanted stem cell transplantation in myeloma? Blood. 2012;120(24):4692-4698.

3. Richardson PG, Hideshima T, Mitsiades C, Anderson KC. The emerging role of novel therapies for the treatment of relapsed myeloma. $J$ Natl Compr Canc Netw. 2007;5(2):149-162.

4. Sonneveld P, Broijl A. Treatment of relapsed and refractory multiple myeloma. Haematologica. 2016;101(4):396-406.

5. Gertz MA, Witzig TE, Pineda AA, Greipp PR, Kyle RA, Litzow MR. Monoclonal plasma cells in the blood stem cell harvest from patients with multiple myeloma are associated with shortened relapse-free survival after transplantation. Bone Marrow Transplant. 1997;19(4):337-342. 
6. Vogel W, Kopp HG, Kanz L, Einsele H. Myeloma cell contamination of peripheral blood stem-cell grafts can predict the outcome in multiple myeloma patients after high-dose chemotherapy and autologous stemcell transplantation. J Cancer Res Clin Oncol. 2005;131(4):214-218.

7. Bashey A, Pérez WS, Zhang MJ, et al. Comparison of twin and autologous transplants for multiple myeloma. Biol Blood Marrow Transplant. 2008;14(10):1118-1124.

8. Alvarnas JC, Forman SJ. Graft purging in autologous bone marrow transplantation: a promise not quite fulfilled. Oncol Williston Park $N$. 2004; 18:867-876

9. Deola S, Scaramuzza S, Birolo RS, et al. Molecular purging of multiple myeloma cells by ex-vivo culture and retroviral transduction of mobilized-blood CD34+ cells. J Transl Med. 2007;5(1):35.

10. Yang H, Robinson SN, Nieto Y, et al. Ex vivo graft purging and expansion of autologous blood progenitor cell products from patients with multiple myeloma. Cancer Res. 2011;71(14):5040-5049.

11. Thirukkumaran CM, Shi ZQ, Luider J, et al. Reovirus as a successful ex vivo purging modality for multiple myeloma. Bone Marrow Transplant. 2014;49(1):80-86.
12. Hideshima T, Richardson P, Chauhan D, et al. The proteasome inhibitor PS-341 inhibits growth, induces apoptosis, and overcomes drug resistance in human multiple myeloma cells. Cancer Res. 2001;61(7):3071-3076.

13. Adams J. The proteasome: structure, function, and role in the cell. Cancer Treat Rev. 2003;29(Suppl 1):3-9.

14. Dick LR, Fleming PE. Building on bortezomib: second-generation proteasome inhibitors as anti-cancer therapy. Drug Discov Today. 2010;15(5-6):243-249.

15. Matsui W, Wang Q, Barber JP, et al. Clonogenic multiple myeloma progenitors, stem cell properties, and drug resistance. Cancer Res. 2008;68(1):190-197.

16. Palumbo A, Miguel JS, Sonneveld P, et al. Lenalidomide: a new therapy for multiple myeloma. Cancer Treat Rev. 2008;34(3):283-291.

17. Kalitin NN, Kostyukova MN, Kakpakova ES, Tupitsyn NN, Karamysheva AF. Expression of vascular endothelial growth factor receptors VEGFR1 in cultured multiple myeloma cells: correlation with immunophenotype and drug resistance. Bull Exp Biol Med 2012;153(6):883-886.
Journal of Blood Medicine

\section{Publish your work in this journal}

The Journal of Blood Medicine is an international, peer-reviewed, open access, online journal publishing laboratory, experimental and clinical aspects of all aspect pertaining to blood based medicine including but not limited to: Transfusion Medicine; Blood collection, Donor issues, Transmittable diseases, and Blood banking logistics; Immunohematology; Artificial and alternative

\section{Dovepress}

blood based therapeutics; Hematology; Biotechnology/nanotechnology of blood related medicine; Legal aspects of blood medicine; Historical perspectives. The manuscript management system is completely online and includes a very quick and fair peer-review system. Visit http://www.dovepress.com/ testimonials.php to read real quotes from published authors. 